\title{
Magnetic resonance imaging - ultrasound fusion targeted biopsy outperforms standard approaches in detecting prostate cancer: A meta-analysis
}

\author{
XUPING JIANG ${ }^{1,2^{*}}$, JIAYI ZHANG ${ }^{2 *}$, JINGYUAN TANG ${ }^{2}$, ZHEN XU $^{2}$, \\ WEI ZHANG ${ }^{2}$, QING ZHANG ${ }^{3}$, HONGQIAN GUO ${ }^{3}$ and WEIMIN ZHOU ${ }^{1}$ \\ ${ }^{1}$ Department of Urology, Yixing People's Hospital, Yixing, Jiangsu 214200; ${ }^{2}$ State Key Laboratory of Reproductive Medicine, \\ Department of Urology, The First Affiliated Hospital of Nanjing Medical University, Nanjing, Jiangsu 210029; \\ ${ }^{3}$ Department of Urology, Drum Tower Hospital, Medical School of Nanjing University, Nanjing, Jiangsu 210008, P.R. China
}

Received February 12, 2016; Accepted May 9, 2016

DOI: $10.3892 / \operatorname{mco} .2016 .906$

\begin{abstract}
The aim of the present study was to determine whether magnetic resonance imaging - ultrasound (MRI-US) fusion prostate biopsy is superior to systematic biopsy for making a definitive diagnosis of prostate cancer. The two strategies were also compared regarding their ability to detect clinically significant and insignificant prostate cancer. A literature search was conducted through the PubMed, EMBASE and China National Knowledge Infrastructure databases using appropriate search terms. A total of 3,415 cases from 21 studies were included in the present meta-analysis. Data were expressed as relative risk (RR) and $95 \%$ confidence interval. The results revealed that MRI-US fusion biopsy achieved a higher rate of overall prostate cancer detection compared with systematic biopsy ( $\mathrm{RR}=1.09 ; \mathrm{P}=0.047$ ). Moreover, MRI-US fusion biopsy detected more clinically significant cancers compared with systematic biopsy $(\mathrm{RR}=1.22 ; \mathrm{P}<0.01)$. It is therefore recommended that multi-parametric MRI-US is performed in men suspected of having prostate cancer to optimize the detection of clinically significant disease, while reducing the burden of biopsies.
\end{abstract}

\section{Introduction}

Prostate cancer is currently one of the most common malignant tumors in men aged $>50$ years. The global age-standardized incidence rate of prostate cancer in 2008

Correspondence to: Dr Weimin Zhou, Department of Urology, Yixing People's Hospital, 75 Tong Zhen Guan Road, Yixing, Jiangsu 214200, P.R. China

E-mail: doctor-zhouwm@163.com

${ }^{*}$ Contributed equally

Key words: fusion image, magnetic resonance imaging, prostate cancer, targeted biopsy, meta-analysis was $\sim 30 / 100,000$ individuals, which is second only to that of lung cancer (1). Screening for prostate cancer mostly relies on digital rectal examination, measurement of prostate-specific antigen (PSA) level, magnetic resonance imaging (MRI) and ultrasound (US). The current standard for diagnosing prostate cancer in men at risk relies on a transrectal US (TRUS)-guided biopsy test, which is blind to cancer location. This method has the advantages of speed, ease, cost-effectiveness, availability and portability, and it is more suitable for wide-area sampling of the prostate, including the far-lateral peripheral zones (2). However, despite an increasing number of biopsy cores being included in TRUS-guided biopsy protocols, the current standard of including 10-14 randomized cores lacks sensitivity and frequently detects clinically insignificant disease (3-5).

It was recently suggested that targeted biopsies of suspicious lesions detected by multi-parametric (mp)-MRI may increase the diagnostic accuracy of TRUS-guided biopsy (6). mp-MRI combines T2-weighted images with diffusion-weighted images and dynamic contrast enhancement $(7,8)$. This method exhibits increased sensitivity and specificity and has become the standard imaging technique for biopsy guidance $(9,10)$. As mp-MRI and biopsy are performed on different days, with the latter commonly performed using a TRUS probe, a number of devices that use image-fusion software have been developed to overlay the suspicious area on mp-MRI onto the US images at the time of biopsy (11).

In the present study, a meta-analysis of data extracted from published studies using MRI-US image fusion targeted prostate biopsy was performed to assess the accuracy of prostate cancer detection compared with that of systematic biopsy.

\section{Materials and methods}

Literature search strategy. A literature search was conducted through the PubMed, EMBASE and China National Knowledge Infrastructure databases for studies published prior to July 21st, 2015, using the key words ('prostate cancer', 'prostate neoplasm' or 'prostate') in combination with ('magnetic resonance imaging', 'MRI' or 'MR') and ('transrectal ultrasound' or 'TRUS') and ('fusion', 'registration', 


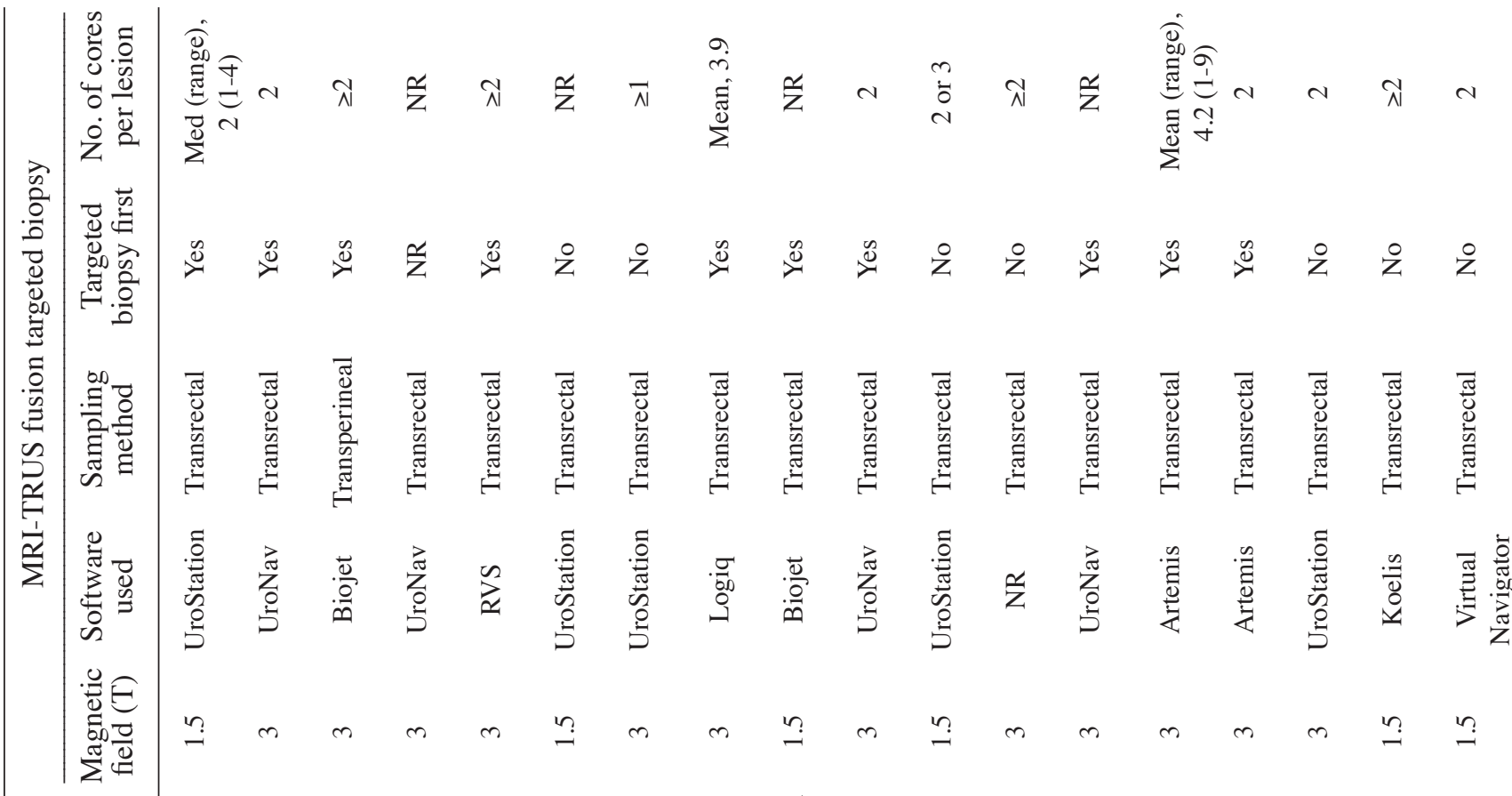

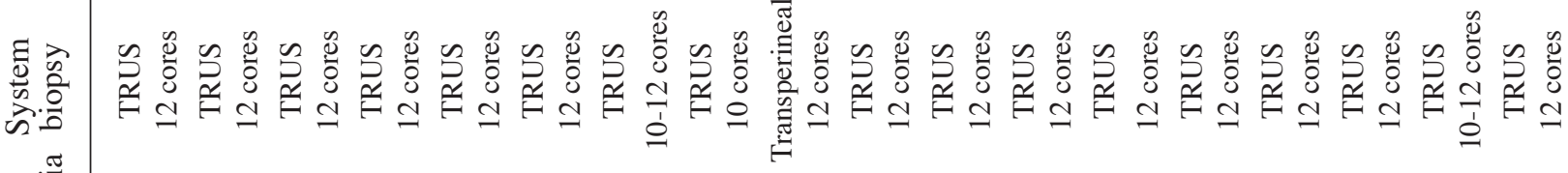

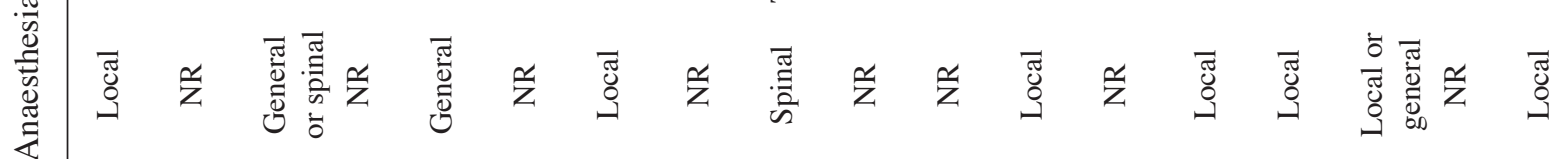

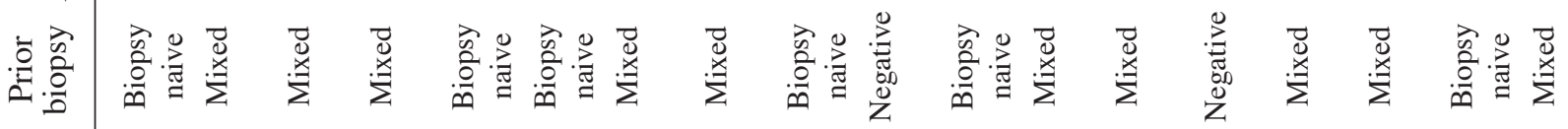

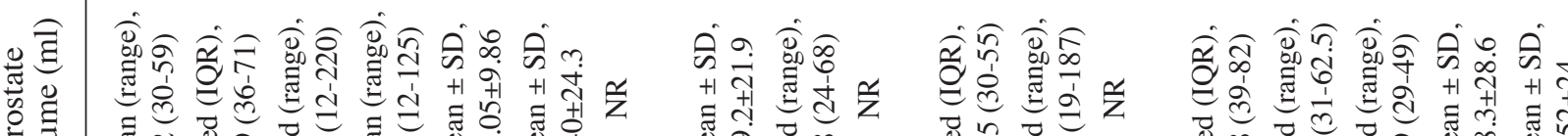

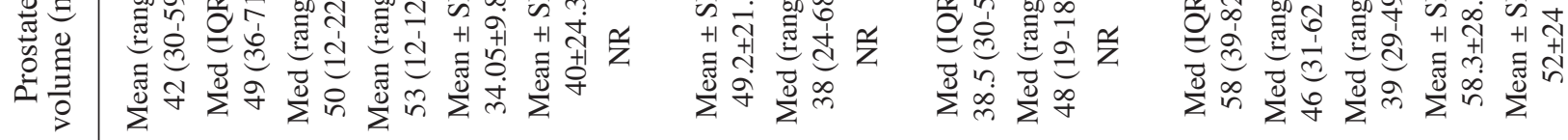

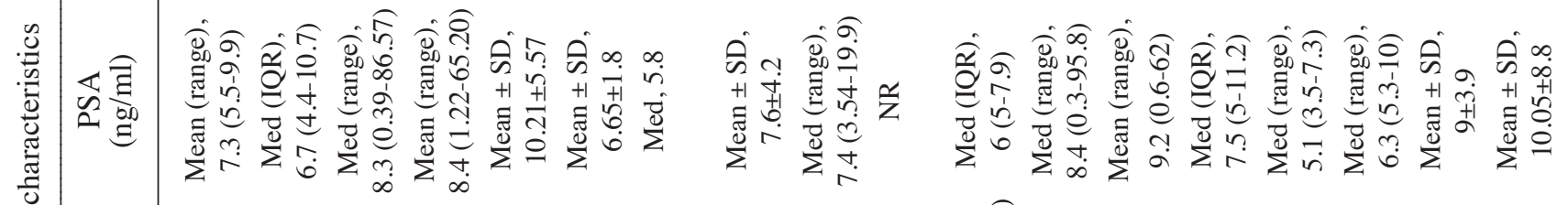

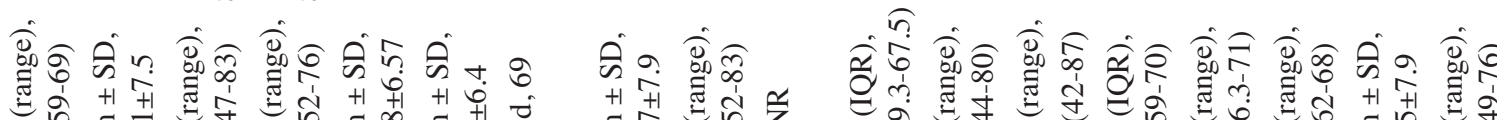

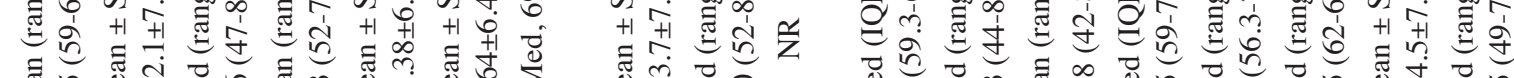

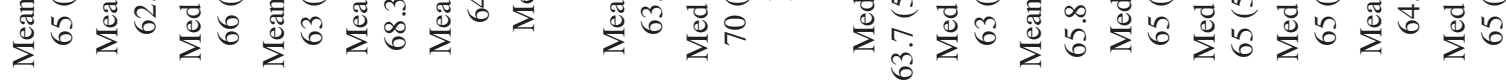

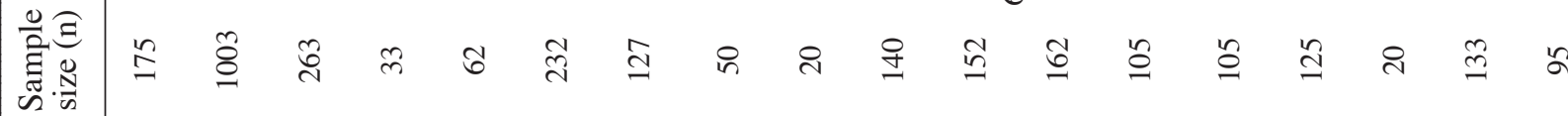

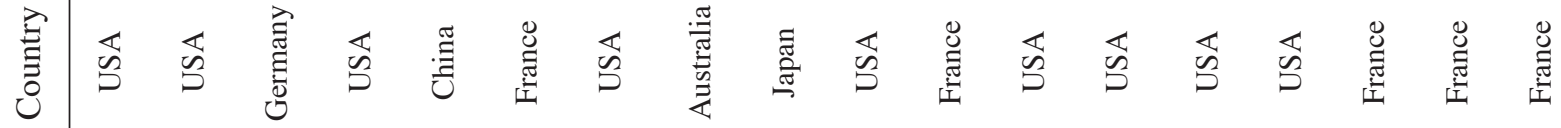

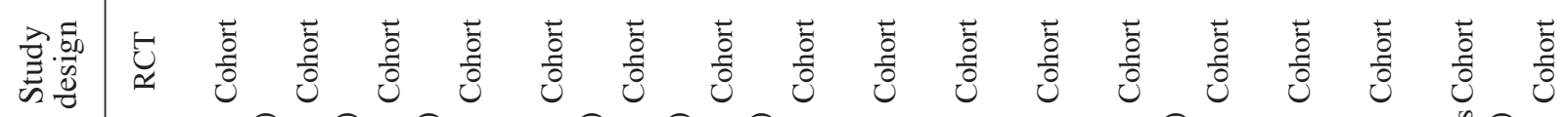




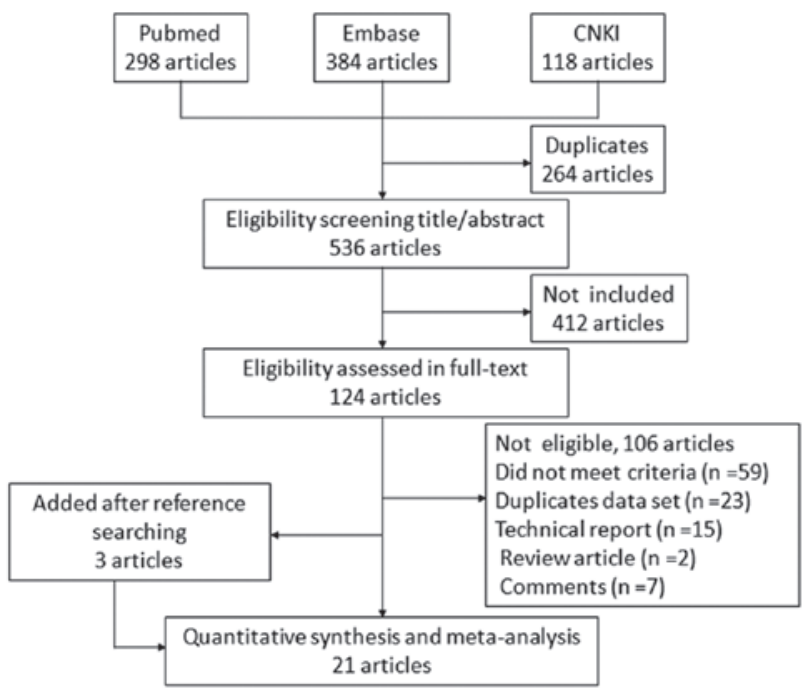

Figure 1. Flow chart of the study selection process. CNKI, China National Knowledge Infrastructure.

'targeted', 'target', 'computer' or 'software'). Only articles written in English or Chinese and studies on human subjects were included. In addition, references of relevant articles were manually searched to identify potentially eligible studies.

Eligibility criteria. Two authors assessed each identified study independently. The inclusion of individual studies required that software-based MRI-US fusion targeted prostate biopsies and systematic biopsies had been performed within the same study. In addition, each study was required to contain overall or significant cancer detection results for the two modalities. To allow for a valid comparison, only studies directly comparing the two techniques were included. When multiple studies contained overlapping data, only the most informative study was included. Meeting abstracts, editorials, case reports, letters and reviews were excluded.

Data extraction. Two investigators blinded to each others' results independently reviewed the full manuscripts of the eligible studies. The information extracted from each study included first author, year of publication, study design, population (sample size, age, PSA, prostate volume and prior biopsy), type of anaesthesia, systematic biopsy (number of cores and sampling route), MRI-US image fusion targeted biopsy procedure (software used, sampling route, time flow and number of cores per lesion) and separate histological outcomes for systematic vs. targeted biopsy (overall detection rate of cancer and detection rate of clinically significant and insignificant cancer). Disagreements between the two reviewers were resolved through discussion.

Statistical analysis. All the analyses were performed using the statistical Stata software, version SE/12 (StataCorp LP, College Station, TX, USA). The main outcome was the detection rate of overall prostate cancer and the secondary outcomes were the detection rates of clinically significant and insignificant disease by MRI-TRUS image fusion targeted biopsy compared with the systematic biopsy technique. The definition used to determine clinical significance was that 
Table II. Quality assessment of the studies included in the meta-analysis.

\begin{tabular}{|c|c|c|c|c|c|c|}
\hline \multirow[b]{2}{*}{$\begin{array}{l}\text { Author, year } \\
\text { (Refs.) }\end{array}$} & \multirow[b]{2}{*}{ Main race } & \multirow[b]{2}{*}{$\begin{array}{l}\text { Definition of clinically } \\
\text { significant disease }\end{array}$} & \multicolumn{2}{|c|}{$\begin{array}{c}\text { Overall cancer } \\
\text { detection (n/total) }\end{array}$} & \multicolumn{2}{|c|}{$\begin{array}{l}\text { Clinically significant } \\
\text { cancer detection (n/total }\end{array}$} \\
\hline & & & $\begin{array}{l}\text { Fusion } \\
\text { biopsy }\end{array}$ & $\begin{array}{l}\text { System } \\
\text { biopsy }\end{array}$ & $\begin{array}{l}\text { Fusion } \\
\text { biopsy }\end{array}$ & $\begin{array}{l}\text { System } \\
\text { biopsy }\end{array}$ \\
\hline Baco et al, 2015 (29) & Caucasian & $\begin{array}{l}\text { Gleason } \geq 7 \text { or maximum } \\
\text { cancer core length } \geq 5 \mathrm{~mm}\end{array}$ & $51 / 86$ & $48 / 89$ & $33 / 86$ & $44 / 89$ \\
\hline Siddiqui et al, 2015 (30) & Caucasian & $\mathrm{NR}$ & $461 / 1,003$ & $469 / 1,003$ & - & - \\
\hline Borkowetz et al, 2015 (31) & Caucasian & $\begin{array}{l}\text { Gleason }>6, \text { or }>2 \text { cores, } \\
\text { or }>50 \% \text { of any core }\end{array}$ & $116 / 263$ & $91 / 263$ & $94 / 263$ & $75 / 263$ \\
\hline Sankineni et al, 2015 (12) & Caucasian & $\begin{array}{l}\text { Gleason }>3+4 \text { with } 25 \% \\
\text { biopsy core involvement }\end{array}$ & $24 / 33$ & $19 / 33$ & $16 / 33$ & $13 / 33$ \\
\hline Zhang et al, 2015 (13) & Asian & $\begin{array}{c}\text { Gleason } \geq 3+4 \text { or } \\
\text { cancer core length } \geq 4 \mathrm{~mm}\end{array}$ & $27 / 62$ & $21 / 62$ & $14 / 62$ & $5 / 62$ \\
\hline de Gorski et al, 2015 (14) & Caucasian & $\begin{array}{c}\text { Gleason } \geq 3+4 \text { or } \\
\text { cancer core length } \geq 4 \mathrm{~mm}\end{array}$ & $126 / 232$ & $129 / 232$ & $102 / 232$ & $91 / 232$ \\
\hline Ukimura et al, 2015 (15) & Caucasian & $\begin{array}{c}\text { Gleason } \geq 3+4 \text { or } \\
\text { cancer core length } \geq 5 \mathrm{~mm}\end{array}$ & $78 / 127$ & $52 / 127$ & $54 / 127$ & $29 / 127$ \\
\hline Junker et al, 2015 (16) & Caucasian & $\mathrm{NR}$ & $23 / 50$ & $18 / 50$ & - & - \\
\hline Shoji et al, 2015 (17) & Asian & NR & $14 / 20$ & $8 / 20$ & - & - \\
\hline Salami et al, 2015 (18) & Caucasian & $\begin{array}{c}\text { Gleason }>6, \text { or }>2 \text { cores, } \\
\text { or }>50 \% \text { of any core }\end{array}$ & $68 / 140$ & $73 / 140$ & $67 / 140$ & $43 / 140$ \\
\hline Mozer et al, 2015 (19) & Caucasian & $\begin{array}{c}\text { Gleason } \geq 3+4 \text { or } \\
\text { cancer core length } \geq 4 \mathrm{~mm}\end{array}$ & $82 / 152$ & $86 / 152$ & $66 / 152$ & $56 / 152$ \\
\hline Volkin et al, 2014 (25) & Caucasian & NR & $19 / 42$ & $18 / 42$ & - & - \\
\hline Rastinehad et al, 2014 (20) & Caucasian & $\begin{array}{c}\text { Gleason }>6, \text { or }>2 \\
\text { cores, or }>50 \% \text { of any core }\end{array}$ & $53 / 105$ & $51 / 105$ & $47 / 105$ & $34 / 105$ \\
\hline Sonn et al, 2014 (26) & Caucasian & $\begin{array}{c}\text { Gleason } \geq 3+4 \text { or } \\
\text { cancer core length } \geq 4 \mathrm{~mm}\end{array}$ & $24 / 102$ & $27 / 97$ & $21 / 102$ & $15 / 97$ \\
\hline Wysock et al, 2014 (27) & Caucasian & Gleason $\geq 3+4$ & $45 / 125$ & $40 / 125$ & $29 / 125$ & $24 / 125$ \\
\hline Fiard et al, 2013 (21) & Caucasian & $\begin{array}{l}\text { Gleason } \geq 3+4 \\
\text { or total cancer length } \geq 10 \mathrm{~mm}\end{array}$ & $11 / 20$ & $10 / 20$ & $10 / 20$ & $9 / 20$ \\
\hline Delongchamps et al, 2013 (23) & Caucasian & NR & $45 / 125$ & $40 / 125$ & - & - \\
\hline Puech et al, 2013 (24) & Caucasian & $\begin{array}{c}\text { Gleason } \geq 3+4 \text { or } \\
\text { cancer core length } \geq 3 \mathrm{~mm}\end{array}$ & $66 / 95$ & $56 / 95$ & $64 / 95$ & $49 / 95$ \\
\hline Kuru et al, 2013 (28) & Caucasian & $\mathrm{NCCN}$ criteria & $128 / 253$ & $161 / 253$ & $104 / 253$ & $121 / 253$ \\
\hline Vourganti et al, 2012 (22) & Caucasian & NR & $56 / 195$ & $45 / 195$ & - & - \\
\hline Miyagawa et al, 2010 (2) & Asian & NR & $45 / 85$ & $34 / 85$ & - & - \\
\hline Total $^{\mathrm{a}}$ & & & $1,562 / 3,315$ & $1,496 / 3,313$ & $721 / 1,795$ & $608 / 1,793$ \\
\hline
\end{tabular}

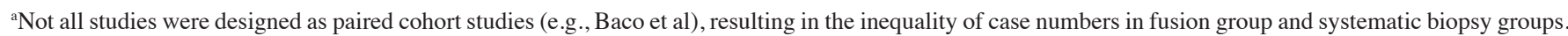
NR, not reported; NCCN, National Comprehensive Cancer Network; system, systematic.

used by each individual study. Fixed-effects or random-effects meta-analysis was performed to pool the original studies on the basis of their relative risk (RR), depending on the result of the heterogeneity analysis. Forest plots were created to summarize all studies, the pooled estimate and corresponding 95\% confidence intervals (95\% CIs) in a single overview.

Heterogeneity was assessed using the $\mathrm{I}^{2}$ statistical method, with $\mathrm{I}^{2}>50 \%$ indicating significant heterogeneity. When heterogeneity was confirmed, a sensitivity analysis was performed by successively excluding each individual study. Subgroup analysis was performed according to several characteristics. Publication bias was assessed using Begg's funnel plot and Egger's test. All the P-values were two-tailed and $\mathrm{P}<0.05$ was considered to indicate statistically significant differences.

\section{Results}

Study selection and characteristics. Of the 800 articles retrieved during the initial search, 21 (2,12-31) met the inclusion criteria. A flow chart of the study selection process is presented in Fig. 1.

A total of 3,415 patients were included, with a sample size ranging from 20 to 1,003 patients. The majority of studies originated from 6 countries, with studies from the USA comprising the largest proportion $(n=10)$. A total of 6 studies 


\begin{tabular}{|c|c|c|}
\hline Study D & RR $(95 \% \mathrm{Cl})$ & Weight $\%$ \\
\hline Baco 2015 & $1.10(0.85,1.43)$ & 5.35 \\
\hline Siddiqui 2015 & $0.98(0.89,1.08)$ & 10.34 \\
\hline Borkowetz 2015 & $1.27(1.03,1.58)$ & 6.49 \\
\hline Sankineni 2015 & $1.26(0.88,1.81)$ & 3.54 \\
\hline Zhang 2015 & $1.29(0.82,2.01)$ & 2.54 \\
\hline deGorski 2015 & $0.98(0.83,1.15)$ & 8.01 \\
\hline Ukimura 2015 & $1.50(1.17,1.93)$ & 5.57 \\
\hline Junker 2015 & $1.28(0.79,2.06)$ & 2.31 \\
\hline Shoj 2015 & $1.75(0.95,3.22)$ & 1.53 \\
\hline Salami 2015 & $0.93(0.74,1.18)$ & 6.00 \\
\hline Mozer 2015 & $0.95(0.78,1.17)$ & 6.84 \\
\hline Volkin 2014 & $1.06(0.65,1.71)$ & 2.27 \\
\hline Rastinehad 2014 & $1.04(0.79,1.37)$ & 5.05 \\
\hline Sonn 2014 & $0.85(0.53,1.36)$ & 2.33 \\
\hline Wysock 2014 & $1.13(0.80,1.59)$ & 3.73 \\
\hline Fiard 2013 & $1.10(0.61,1.99)$ & 1.61 \\
\hline Puech 2013 & $1.18(0.95,1.46)$ & 6.50 \\
\hline Kuru 2013 & $0.80(0.68,0.93)$ & 8.39 \\
\hline Vourganti 2012 & $1.24(0.89,1.75)$ & 3.85 \\
\hline Myagawa 2010 & $1.32(0.95,1.84)$ & 4.01 \\
\hline Delongchamps 2013 & $1.13(0.80,1.59)$ & 3.73 \\
\hline Overall (l-squared $=47.8 \%, p=0.008$ ) & $1.09(1.00,1.18)$ & 100.00 \\
\hline \multicolumn{3}{|l|}{ NOTE: Weights are from random effects analysis } \\
\hline $\begin{array}{ll}1 & 1 \\
0.311 & 1\end{array}$ & 3.22 & \\
\hline
\end{tabular}

Figure 2. Forest plots of the RR with 95\% CI for the heterogeneity of overall prostate cancer detection (MRI-US fusion biopsy vs. systematic biopsy) determined by the random-effects model. $\chi^{2}=38.34, \mathrm{P}=0.008, \mathrm{I}^{2}=47.8 \%, \mathrm{Z}=1.99$ and $\mathrm{P}=0.047$. The grey square indicates the value of $\mathrm{RR}$ and its size is inversely proportional to its variance. The horizontal line represents the $95 \%$ CI of the RR. The white diamond represents the pooled results. The studies are ordered by the publication year. RR, relative risk; CI, confidence interval; MRI, magnetic resonance imaging; US, ultrasound.

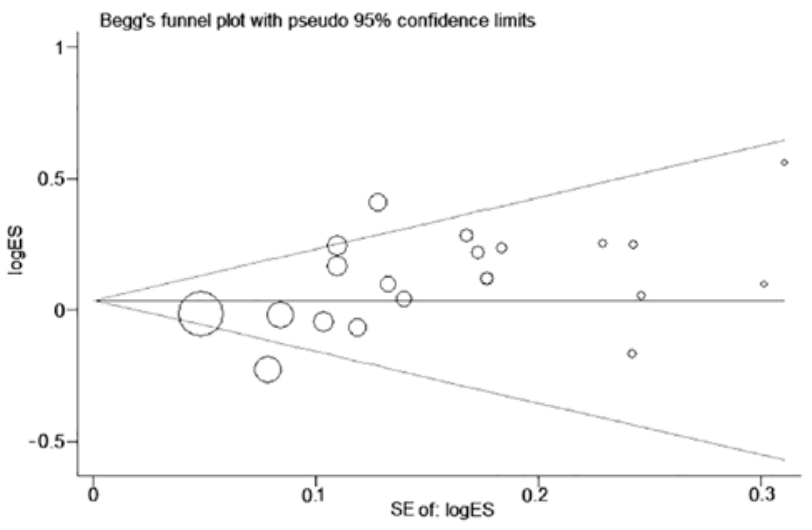

Figure 3. Begg's funnel plot for the assessment of publication bias for overall prostate cancer detection. Begg's test, $\mathrm{P}=0.205$; Egger's test, $\mathrm{P}=0.017$. The horizontal line represents the summary estimate, while the sloping lines represent the expected $95 \%$ confidence interval. The case numbers in Wysock's and Delongchamps's studies were identical, leading to the superposition of the respective circles in the funnel plot. $\log E S$, natural logarithm of effect size; SE, standard error.

had been conducted on biopsy-naive patients, 4 on patients with a previous negative prostate biopsy, and 11 studies reported on a mixed cohort (either biopsy-naive patients, or those having undergone previous prostate biopsy). All mp-MRI scans had been performed on either a 1.5- or a 3-T scanner and 9 different image fusion platforms currently used in the clinical setting to perform MRI-TRUS targeted biopsies were identified in this meta-analysis. The standard comparator was a 8- to 12-core TRUS biopsy in 18 studies, whereas 3 other studies used transperineal template biopsies, or a combination of the two.
The characteristics of the included studies are summarized in Table I.

Overall prostate cancer detection. Details regarding diagnostic criteria and detection ratios in the individual studies are presented in Table II. Across the 21 studies, the prevalence of prostate cancer was $63.0 \%(2,153 / 3,415)$. MRI-US fusion biopsy detected overall prostate cancer in 1,562 of 3,315 patients and systematic biopsy in 1,496 of 3,313 patients, resulting in an RR of 1.09 (95\% CI: 1.00-1.18; $\mathrm{P}=0.047$ ) (Fig. 2). The heterogeneity among these studies was moderate $\left(\mathrm{I}^{2}=47.8 \% ; \chi^{2}=38.34 ; \mathrm{P}=0.047\right)$. Publication bias in this overall analysis was revealed by the Begg's funnel plot $(\mathrm{P}=0.205$, Begg's test; $\mathrm{P}=0.017$, Egger's test) (Fig. 3).

Clinically significant prostate cancer detection. A total of 14 studies including 1,884 patients were eligible for inclusion in the analysis. The prevalence of clinically significant and insignificant prostate cancer was $47.2 \%(890 / 1,884)$ and $16.6 \%(313 / 1,884)$, respectively. Clinically significant prostate cancer was diagnosed in 721 of the 1,795 patients with MRI-US fusion biopsy compared with 608 of 1,793 patients with systematic biopsy, with an RR of 1.22 (95\% CI: 1.06-1.40; $\mathrm{P}=0.005$ ) (Fig. 4). However, heterogeneity was observed among these studies $\left(\mathrm{I}^{2}=56.7 \% ; \chi^{2}=30.04\right.$; $\mathrm{P}=0.005)$. Begg's funnel plots revealed little publication bias in this analysis (Fig. 5), whereas the Egger's and Begg's tests indicated there was no publication bias.

The results of the subgroup analysis for clinically significant prostate cancer detection are presented in Table III. MRI-US 


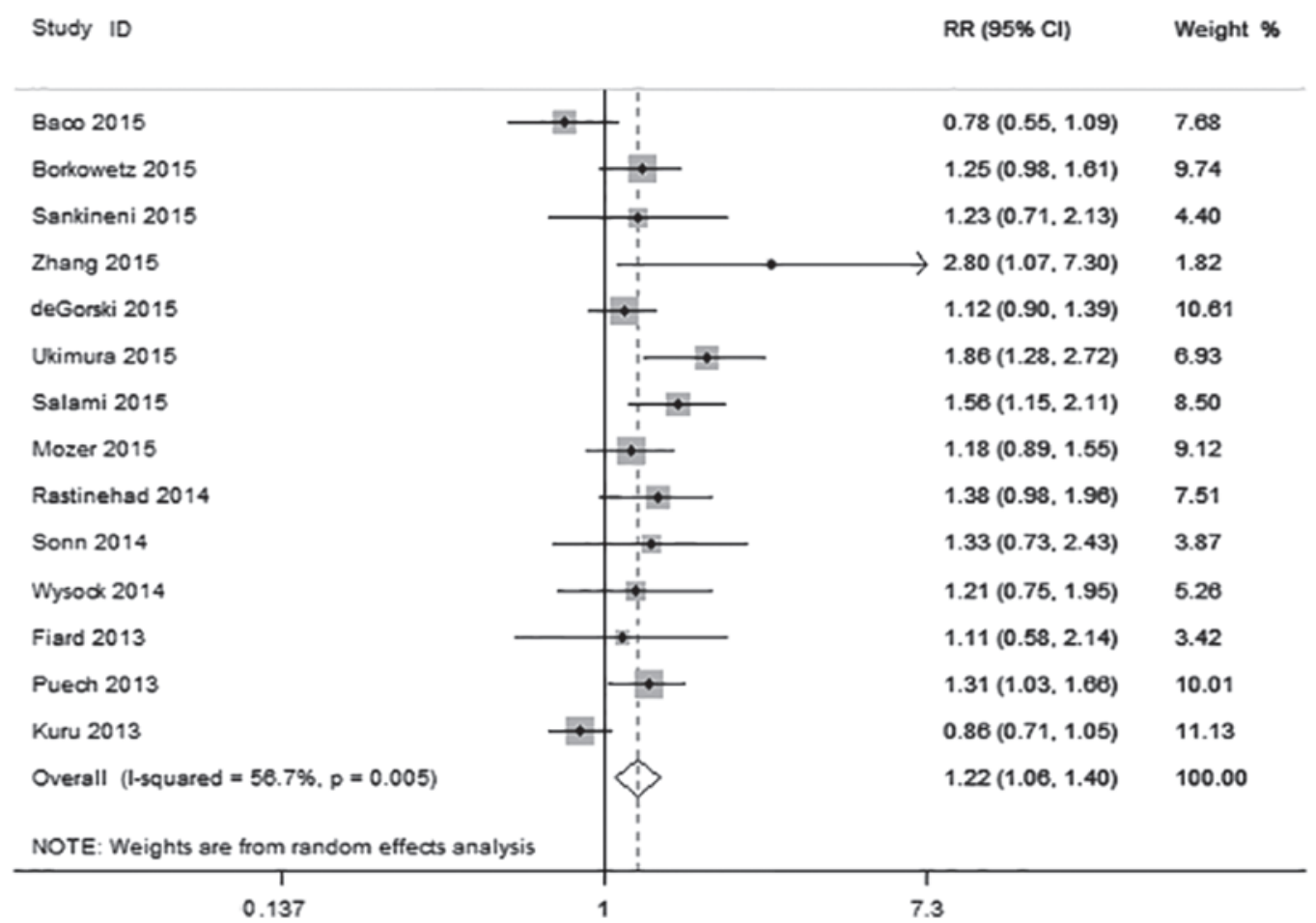

Figure 4. Forest plots of the RR with $95 \%$ CI for the heterogeneity of clinically significant prostate cancer detection (MRI-US fusion biopsy vs. systematic biopsy) determined by the random-effects model. $\chi^{2}=30.04, \mathrm{P}=0.005, \mathrm{I}^{2}=56.7 \%, \mathrm{Z}=2.79$ and $\mathrm{P}=0.005$. The grey square indicates the value of $\mathrm{RR}$ and the size of the square is inversely proportional to its variance. The horizontal line represents the $95 \% \mathrm{CI}$ of the RR. Tthe white diamond indicates the pooled results. The studies are ordered by publication year. RR, relative risk; CI, confidence interval; MRI, magnetic resonance imaging; US, ultrasound.

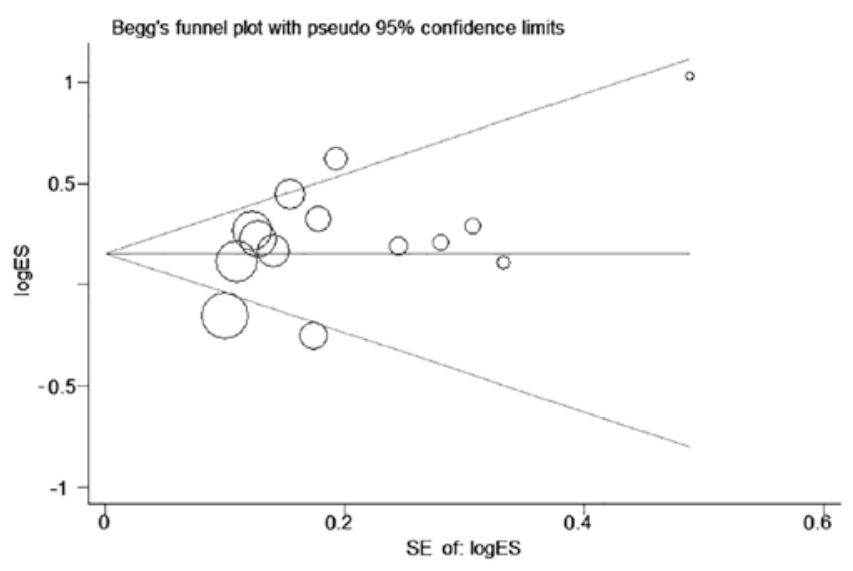

Figure 5. Begg's funnel plot for the assessment of publication bias for clinically significant prostate cancer detection. Begg's test, $\mathrm{P}=0.274$; Egger's test, $\mathrm{P}=0.124$. The horizontal line represents the summary estimate, while the sloping lines represent the expected $95 \%$ confidence interval. $\log \mathrm{ES}$, natural logarithm of effect size; SE, standard error.

fusion biopsy exhibited a significantly higher detection rate of clinically significant prostate cancer compared with systematic biopsy in 7 subgroups, but there was heterogeneity in all subgroups apart from that of patients with a previous negative biopsy.

Sensitivity analysis of the 14 studies demonstrated that the results of Kuru et al (28) diverged from those of most other trials (Fig. 6). Following exclusion of the Kuru et al trial, there was no significant variation in the RR value, but the heterogeneity decreased (Table IV).
Clinically insignificant prostate cancer was diagnosed in 178 of 1,795 patients by MRI-US fusion biopsy and in 256 of 1,793 patients by systematic biopsy, resulting in a RR of 0.73 (95\% CI: 0.51-1.05; $\mathrm{P}=0.089$ ); there was high heterogeneity among these studies $\left(\mathrm{I}^{2}=67.5 \% ; \chi^{2}=39.97 ; \mathrm{P}<0.01\right)$.

\section{Discussion}

The current gold standard technique for diagnosing prostate cancer in men at risk is systematic prostate biopsy using TRUS. However, there are discrepancies between the results of systematic prostate biopsy and radical prostatectomy specimens (32), as only $24-40 \%$ of TRUS-guided biopsy results are consistent with the pathological findings following prostatectomy (33). Furthermore, systematic biopsy may not be able to detect all cases of clinically significant prostate cancer, which may delay the treatment of a tumor with a high Gleason score (3-5). The optimal biopsy strategy should selectively detect clinically significant prostate cancer and minimize clinically insignificant prostate cancer detection to avoid consequent overtreatment. The present meta-analysis demonstrated that MRI-US fusion targeted biopsy may be a promising strategy with certain advantages over systematic biopsy.

The results of the present study demonstrated that the overall prostate cancer detection rate of MRI-US fusion biopsy is higher compared with that of systematic biopsy, with an RR of 1.09. The difference between the results of the present study and those of a prior systematic review (34) may be due to the larger sample size and updated data included herein. 
Table III. Results of subgroup analysis of significant prostate cancer detection.

\begin{tabular}{|c|c|c|c|c|c|c|}
\hline \multirow[b]{2}{*}{ Subgroups } & \multirow[b]{2}{*}{ No. of studies } & \multicolumn{2}{|c|}{ Heterogeneity } & \multirow[b]{2}{*}{ Effects model } & \multicolumn{2}{|c|}{ Meta-analysis } \\
\hline & & $\mathrm{I}^{2}(\%)$ & P-value & & $\mathrm{RR}(95 \% \mathrm{CI})$ & P-value \\
\hline \multicolumn{7}{|l|}{ Study design } \\
\hline Paired cohort & 13 & 50.3 & 0.02 & Random & $1.258(1.100-1.438)$ & 0.001 \\
\hline Comparative series & 1 & - & - & - & $0.776(0.552-1.091)$ & 0.145 \\
\hline \multicolumn{7}{|l|}{ Main race } \\
\hline Caucasian & 13 & 55.2 & 0.008 & Random & $1.198(1.047-1.370)$ & 0.009 \\
\hline Asian & 1 & - & - & - & $2.800(1.074-7.302)$ & 0.035 \\
\hline \multicolumn{7}{|l|}{ Prior biopsy } \\
\hline Mixed & 8 & 59.8 & 0.015 & Random & $1.235(1.023-1.491)$ & 0.028 \\
\hline Biopsy naive & 4 & 62.4 & 0.047 & Random & $1.101(0.833-1.457)$ & 0.498 \\
\hline Previous negative & 2 & 0.0 & 0.645 & Fixed & $1.498(1.141-1.967)$ & 0.004 \\
\hline \multicolumn{7}{|c|}{ Strength of magnetic field } \\
\hline $3 \mathrm{~T}$ & 10 & 61.5 & 0.005 & Random & $1.311(1.073-1.601)$ & 0.008 \\
\hline $1.5 \mathrm{~T}$ & 4 & 51.6 & 0.102 & Random & $1.104(0.914-1.333)$ & 0.307 \\
\hline \multicolumn{7}{|l|}{ Sampling method } \\
\hline Transrectal & 12 & 40.3 & 0.072 & Random & 1.269 (1.104-1.459) & 0.001 \\
\hline Transperineal & 2 & 81.7 & 0.019 & Random & $1.029(0.710-1.492)$ & 0.879 \\
\hline
\end{tabular}

RR, relative risk; CI, confidence interval.

Table IV. Results of sensitivity analysis of significant prostate cancer detection.

\begin{tabular}{llllr}
\hline \multirow{2}{*}{ Sensitivity analysis } & \multicolumn{2}{c}{ Heterogeneity test } & \multicolumn{2}{c}{ Pooled estimate } \\
\cline { 2 - 4 } & $\mathrm{I}^{2}(\%)$ & $\operatorname{tau}^{2}$ & RR (95\% CI) & P-value \\
\hline Kuru et al $(28)$ incorporated & 56.7 & 0.0350 & $1.218(1.060,1.399)$ & 0.005 \\
Kuru et al $(28)$ excluded & 34.8 & 0.0162 & $1.265(1.119,1.429)$ & $<0.001$ \\
\hline
\end{tabular}

$\mathrm{RR}$, relative risk; CI, confidence interval.

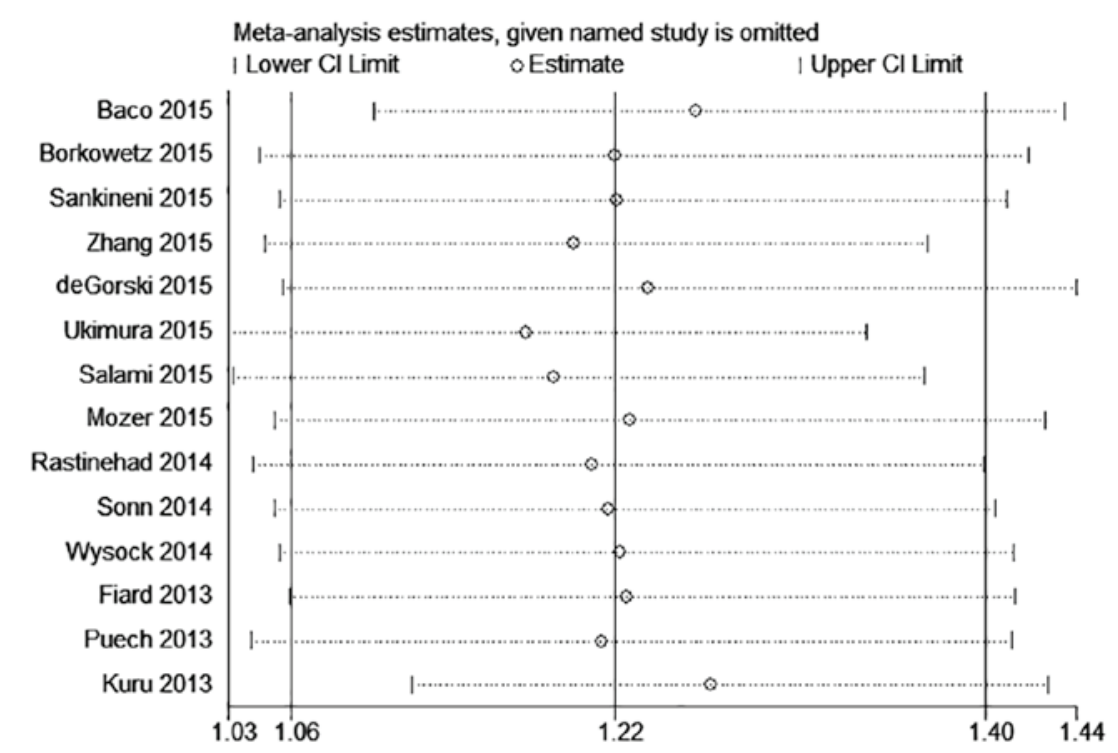

Figure 6. Sensitivity analysis of the RR with $95 \%$ CI of clinically significant prostate cancer detection (MRI-US fusion biopsy vs. systematic biopsy). The circles represent the RR estimate and the horizontal lines represent the $95 \% \mathrm{CI}$. The studies are ordered by publication year. MRI, magnetic resonance imaging; US, ultrasound; CI, confidence interval; RR, relative risk. 
It was reported that mp-MRI exhibits a high diagnosis rate of clinically significant prostate cancer when compared to the histological findings following radical prostatectomy (35), which is in line with the results of the present study. In our study, MRI-US fusion biopsy had an RR of 1.22 for detecting significant prostate cancer, which means that MRI-US fusion biopsy has a $22 \%$ increased detection rate for clinically significant prostate cancer compared with systematic biopsy.

MRI-US fusion biopsy and systematic biopsy did not significantly differ in the detection of clinically insignificant prostate cancer; however, an RR of 0.73 indicated that MRI-US had a better performance in terms of avoiding detection of insignificant prostate cancer compared with systematic biopsy in most studies. Thus, the application of MRI-US fusion biopsy may help reduce oversampling of potentially insignificant prostate cancers.

Several studies also compared MRI-US fusion with the systematic approach on a per-core basis $(13,21,30)$. The results demonstrated that MRI-US-guided biopsy required fewer cores for successful tumor detection, thereby reducing patient discomfort compared with systematic biopsy.

The present meta-analysis had several limitations that may reduce the strength of the conclusions. Studies with negative results are less likely to be published, which may result in the overstatement of beneficial effects in meta-analyses. In the analysis of the overall prostate cancer detection rate, Begg's test yielded a P-value of 0.205, while Egger's test yielded a $\mathrm{P}$-value of 0.017 , indicating the presence of publication bias, as Egger's test has a higher sensitivity.

In the analysis of the detection of clinically significant prostate cancer, Begg's test and Egger's test indicated no publication bias. However, significant heterogeneity was found in this analysis $\left(\mathrm{I}^{2}=56.7 \%\right)$. Subgroup analysis revealed the presence of heterogeneity in all subgroups apart from that including patients with a previous negative biopsy, indicating that the heterogeneity originated in the category of prior biopsy, but not study design, main race, strength of magnetic field or sampling method. The sensitivity analysis revealed that, after excluding the trial by Kuru et al (28), heterogeneity was markedly decreased, while the RR value was not significantly affected. Kuru et al (28) obtained a higher RR compared with that of the other studies, possibly due to the BiopSee system used in their study, in which US, TRUS/MRI fusion, biopsy planning, perineal targeting, 3D mapping and automated documentation are integrated into a single system. The definition of significant prostate cancer, which included intermediate or high-risk tumors according to the National Comprehensive Cancer Network criteria (36), may also explain their higher RR. In addition, significant heterogeneity may be attributed to the variability across the studies in terms of criteria for defining clinically significant tumors, the methodology of targeted biopsy and the number of cores per target.

On the basis of biopsy data alone, it may be methodologically incorrect to conclude that MRI-US fusion biopsy detects more significant prostate cancers compared with systematic biopsy. This conclusion may be a statistical or methodological effect rather than a true clinical fact. All patients would have to undergo radical prostatectomy and assessment of the final pathology to draw clinically relevant conclusions. Such studies are warranted in the future.

In summary, a meta-analysis of the currently available high-level clinical studies was performed to evaluate the efficacy of MRI-US fusion prostate biopsy. It was revealed that MRI-US fusion prostate biopsy has a higher detection rate of prostate cancer compared with systematic biopsy. MRI-US fusion biopsy also detects more clinically significant and fewer insignificant prostate cancers compared with systematic protocols. It is therefore recommended that mp-MRI is performed in patients suspected of having prostate cancer in order to optimize the detection of clinically significant prostate cancer, while reducing the burden of biopsies.

\section{Acknowledgements}

The present study was supported by the National Natural Science Foundation of China (grant no. 81370781).

\section{References}

1. Soerjomataram I, Lortet-Tieulent J, Parkin DM, Ferlay J, Mathers C, Forman D and Bray F: Global burden of cancer in 2008: A systematic analysis of disability-adjusted life-years in 12 world regions. Lancet 380: 1840-1850, 2012.

2. Miyagawa T, Ishikawa S, Kimura T, Suetomi T, Tsutsumi M, Irie T, Kondoh M and Mitake T: Real-time virtual sonography for navigation during targeted prostate biopsy using magnetic resonance imaging data. Int J Urol 17: 855-860, 2010.

3. Babaian RJ, Toi A, Kamoi K, Troncoso P, Sweet J, Evans R, Johnston D and Chen M: A comparative analysis of sextant and an extended 11-core multisite directed biopsy strategy. J Urol 163: 152-157, 2000.

4. Presti JC Jr, O'Dowd GJ, Miller MC, Mattu R and Veltri RW: Extended peripheral zone biopsy schemes increase cancer detection rates and minimize variance in prostate specific antigen and age related cancer rates: Results of a community multi-practice study. J Urol 169: 125-129, 2003.

5. Campos-Fernandes JL, Bastien L, Nicolaiew N, Robert G, Terry S, Vacherot F, Salomon L, Allory Y, Vordos D, Hoznek A, et al: Prostate cancer detection rate in patients with repeated extended 21-sample needle biopsy. Eur Urol 55: 600-606, 2009.

6. Sonn GA, Margolis DJ and Marks LS: Target detection: Magnetic resonance imaging-ultrasound fusion-guided prostate biopsy. Urol Oncol 32: 903-911, 2014.

7. Dickinson L, Ahmed HU, Allen C, Barentsz JO, Carey B, Futterer JJ, Salomon L, Allory Y, Vordos D, Hoznek A, et al: Magnetic resonance imaging for the detection, localisation, and characterisation of prostate cancer: Recommendations from a European consensus meeting. Eur Urol 59: 477-494, 2011.

8. Barentsz JO, Richenberg J, Clements R, Choyke P, Verma S, Villeirs G, Rouviere O, Logager V and Fütterer JJ; European Society of Urogenital Radiology: ESUR prostate MR guidelines 2012. Eur Radiol 22: 746-757, 2012.

9. Haffner J, Lemaitre L, Puech P, Haber GP, Leroy X, Jones JS and Villers A: Role of magnetic resonance imaging before initial biopsy: Comparison of magnetic resonance imaging-targeted and systematic biopsy for significant prostate cancer detection. BJU Int 108: E171-E178, 2011.

10. Hambrock T, Somford DM, Hoeks C, Bouwense SA, Huisman H, Yakar D, van Oort IM, Witjes JA, Fütterer JJ and Barentsz JO: Magnetic resonance imaging guided prostate biopsy in men with repeat negative biopsies and increased prostate specific antigen. J Urol 183: 520-527, 2010.

11. Moore CM, Robertson NL, Arsanious N, Middleton T, Villers A, Klotz L, Taneja SS and Emberton M: Image-guided prostate biopsy using magnetic resonance imaging-derived targets: A systematic review. Eur Urol 63: 125-140, 2013.

12. Sankineni S, George AK, Brown AM, Rais-Bahrami S, Wood BJ, Merino MJ, Pinto PA, Choyke PL and Turkbey B: Posterior subcapsular prostate cancer: Identification with mpMRI and MRI/TRUS fusion-guided biopsy. Abdom Imaging 40: 2557-2565, 2015 . 
13. Zhang Q, Wang W, Yang R, Zhang G, Zhang B, Li W, Huang H and Guo H: Free-hand transperineal targeted prostate biopsy with real-time fusion imaging of multiparametric magnetic resonance imaging and transrectal ultrasound: Single-center experience in China. Int Urol Nephrol 47: 727-733, 2015.

14. de Gorski A, Rouprêt M, Peyronnet B, Le Cossec C, Granger B, Comperat $\mathrm{E}$ and Cussenot $\mathrm{O}$ : Accuracy of magnetic resonance imaging/ultrasound fusion targeted biopsies to diagnose clinical significant prostate cancer in enlarged compared to smaller prostates. J Urol 194: 669-673, 2015.

15. Ukimura O, Marien A, Palmer S, Villers A, Aron M, de Castro AA, Leslie S, Shoji S, Matsugasumi T, Gross M, et al: Trans-rectal ultrasound visibility of prostate lesions identified by magnetic resonance imaging increases accuracy of image-fusion targeted biopsies. World J Urol 33: 1669-1676, 2015.

16. Junker D, Schäfer G, Heidegger I, Bektic J, Ladurner M, Jaschke W and Aigner F: Multiparametric magnetic resonance imaging/transrectal ultrasound fusion targeted biopsy of the prostate: Preliminary results of a prospective single-centre study. Urol Int 94: 313-318, 2015.

17. Shoji S, Hiraiwa S, Endo J, Hashida K, Tomonaga T, Nakano M, Sugiyama T, Tajiri T, Terachi $\mathrm{T}$ and Uchida T: Manually controlled targeted prostate biopsy with real-time fusion imaging of multiparametric magnetic resonance imaging and transrectal ultrasound: An early experience. Int J Urol 22: 173-178, 2015.

18. Salami SS, Ben-Levi E, Yaskiv O, Ryniker L, Turkbey B, Kavoussi LR, Villani R and Rastinehad AR: In patients with a previous negative prostate biopsy and a suspicious lesion on magnetic resonance imaging, is a 12-core biopsy still necessary in addition to a targeted biopsy? BJU Int 115: 562-570, 2015.

19. Mozer P, Rouprêt M, Le Cossec C, Granger B, Comperat E, de Gorski A, Cussenot $\mathrm{O}$ and Renard-Penna R: First round of targeted biopsies using magnetic resonance imaging/ultrasonography fusion compared with conventional transrectal ultrasonography-guided biopsies for the diagnosis of localised prostate cancer. BJU Int 115: 50-57, 2015.

20. Rastinehad AR, Turkbey B, Salami SS, Yaskiv O, George AK, Fakhoury M, Beecher K, Vira MA, Kavoussi LR, Siegel DN, et al: Improving detection of clinically significant prostate cancer: Magnetic resonance imaging/transrectal ultrasound fusion guided prostate biopsy. J Urol 191: 1749-1754, 2014.

21. Fiard G, Hohn N, Descotes JL, Rambeaud JJ, Troccaz J and Long JA: Targeted MRI-guided prostate biopsies for the detection of prostate cancer: Initial clinical experience with real-time 3-dimensional transrectal ultrasound guidance and magnetic resonance/transrectal ultrasound image fusion. Urology 81: 1372-1378, 2013.

22. Vourganti S, Rastinehad A, Yerram NK, Nix J, Volkin D, Hoang A, Turkbey B, Gupta GN, Kruecker J, Linehan WM, et al: Multiparametric magnetic resonance imaging and ultrasound fusion biopsy detect prostate cancer in patients with prior negative transrectal ultrasound biopsies. J Urol 188: 2152-2157, 2012.

23. Delongchamps NB, Peyromaure M, Schull A, Beuvon F Bouazza N, Flam T, Zerbib M, Muradyan N, Legman P and Cornud F: Prebiopsy magnetic resonance imaging and prostate cancer detection: Comparison of random and targeted biopsies. J Urol 189: 493-499, 2013.

24. Puech P, Rouvière O, Renard-Penna R, Villers A, Devos P, Colombel M, Bitker MO, Leroy X, Mège-Lechevallier F, Comperat E, et al: Prostate cancer diagnosis: Multiparametric MR-targeted biopsy with cognitive and transrectal US-MR fusion guidance versus systematic biopsy-prospective multicenter study. Radiology 268: 461-469, 2013.
25. Volkin D, Turkbey B, Hoang AN, Rais-Bahrami S, Yerram N, Walton-Diaz A, Nix JW, Wood BJ, Choyke PL and Pinto PA: Multiparametric magnetic resonance imaging (MRI) and subsequent MRI/ultrasonography fusion-guided biopsy increase the detection of anteriorly located prostate cancers. BJU Int 114: E43-E49, 2014.

26. Sonn GA, Chang E, Natarajan S, Margolis DJ, Macairan M, Lieu P, Nix JW, Wood BJ, Choyke PL and Pinto PA: Value of targeted prostate biopsy using magnetic resonance-ultrasound fusion in men with prior negative biopsy and elevated prostate-specific antigen. Eur Urol 65: 809-815, 2014.

27. Wysock JS, Rosenkrantz AB, Huang WC, Stifelman MD, Lepor H, Deng FM, Melamed J and Taneja SS: A prospective, blinded comparison of magnetic resonance (MR) imaging-ultrasound fusion and visual estimation in the performance of MR-targeted prostate biopsy: The PROFUS trial. Eur Urol 66: 343-351, 2014.

28. Kuru TH, Roethke MC, Seidenader J, Simpfendörfer T, Boxler S, Alammar K, Rieker P, Popeneciu VI, Roth W, Pahernik S, et al: Critical evaluation of magnetic resonance imaging targeted, transrectal ultrasound guided transperineal fusion biopsy for detection of prostate cancer. J Urol 190: 1380-1386, 2013.

29. Baco E, Rud E, Eri LM, Moen G, Vlatkovic L, Svindland A, Eggesb $\varnothing \mathrm{HB}$ and Ukimura O: A randomized controlled trial to assess and compare the outcomes of two-core prostate biopsy guided by fused magnetic resonance and transrectal ultrasound images and traditional 12-core systematic biopsy. Eur Urol 69: 149-156, 2016.

30. Siddiqui MM, Rais-Bahrami S, Turkbey B, George AK, Rothwax J, Shakir N, Okoro C, Raskolnikov D, Parnes HL, Linehan WM, et al: Comparison of MR/ultrasound fusion-guided biopsy with ultrasound-guided biopsy for the diagnosis of prostate cancer. JAMA 313: 390-397, 2015.

31. Borkowetz A, Platzek I, Toma M, Laniado M, Baretton G, Froehner M, Koch R, Wirth M and Zastrow S: Comparison of systematic transrectal biopsy to transperineal magnetic resonance imaging/ultrasound-fusion biopsy for the diagnosis of prostate cancer. BJU Int 116: 873-879, 2015.

32. Ploussard G, Salomon L, Xylinas E, Allory Y, Vordos D, Hoznek A, Abbou CC and de la Taille A: Pathological findings and prostate specific antigen outcomes after radical prostatectomy in men eligible for active surveillance - does the risk of misclassification vary according to biopsy criteria? J Urol 183: $539-544,2010$

33. Dominguez-Escrig JL, McCracken SR and Greene D: Beyond diagnosis: Evolving prostate biopsy in the era of focal therapy. Prostate Cancer 2011: 386207, 2011.

34. Valerio M, Donaldson I, Emberton M, Ehdaie B, Hadaschik BA, Marks LS, Mozer P, Rastinehad AR and Ahmed HU: Detection of clinically significant prostate cancer using magnetic resonance imaging-ultrasound fusion targeted biopsy: A systematic review. Eur Urol 68: 8-19, 2015.

35. Puech P, Potiron E, Lemaitre L, Leroy X, Haber GP, Crouzet S, Kamoi K and Villers A: Dynamic contrast-enhanced-magnetic resonance imaging evaluation of intraprostatic prostate cancer: Correlation with radical prostatectomy specimens. Urology 74: 1094-1099, 2009.

36. Carroll PR, Parsons JK, Andriole G, Bahnson RR, Castle EP, Catalona WJ, Dahl DM, Davis JW, Epstein JI, Etzioni RB, et al: NCCN Guidelines Insights: Prostate Cancer Early Detection, Version 2.2016. J Natl Compr Canc Netw 14: 509-519, 2016. 